\title{
Kemenarikan Iklan OMO! Healthy Snack dalam Membangun Brand Awareness di Media Sosial
}

\author{
https://doi.org/10.25008/caraka.v2i2.62 \\ Verlita Evelyn Raimond \\ Sekolah Tinggi Ilmu Komunikasi (STIKOM) InterStudi - Jakarta
}

\begin{abstract}
This research departs from increasing popularity of social media in business activities, especially brand advertisement display. This study concerned with OMO! Healthy Snack brand, a healthy local Indonesian snack brand for children. This study aims to examine the attractiveness of the OMO! Healthy Snack brand advertisement on Instagram social media in building brand awareness. This study uses Husserlian phenomenological framework and Blumerian symbolic interactionism to describe the interaction between brand owners and brand buyers. This research is located in DKI Jakarta and uses an interpretive paradigm and uses qualitative methods. The subjects involved in this study are owners of the OMO! Healthy Snack brand and buyers of the OMO! Healthy Snack brand. This study conclude that buyers are visually attracted and associate the OMO! Healthy Snack brand advertisement with the children's world, and the owner of OMO! Healthy Snack brand makes the OMO! Healthy Snack brand advertisement a medium for educating healthy snacks for mothers. This study wants to contribute to communication studies, especially brand communication by emphasizing active process of consumers in interpreting symbols displayed by brand owners through advertising displays.
\end{abstract}

Keyword: advertisement; brand awareness; phenomenology; social media; symbolic interactionism.

\section{ABSTRAK}

Penelitian ini berangkat dari latar belakang berupa semakin populernya media sosial dalam kegiatan bisnis khususnya untuk menampilkan iklan suatu brand. Penelitian ini mengangkat brand OMO! Healthy Snack, yaitu suatu brand makanan ringan produksi lokal Indonesia yang sehat bagi anak-anak. Penelitian ini bertujuan untuk menelaah kemenarikan iklan brand OMO! Healthy Snack di media sosial Instagram dalam membangun brand awareness. Kajian ini menggunakan kerangka pikir fenomenologi Edmund Husserl dan interaksionisme simbolik Herbert Blumer untuk mengurai interaksi antara pemilik brand dan pembeli brand. Penelitian ini berlokasi di Jakarta dan menggunakan paradigma interpretif dan memakai metode kualitatif. Subyek yang telibat dalam kajian ini adalah pemilik brand OMO! Healthy Snack dan pembeli brand OMO! Healthy Snack. Hasil penelitian ini menyimpulkan, pembeli tertarik secara visual dan mengasosiasikan iklan brand OMO! Healthy Snack dengan dunia anak-anak, dan pemilik brand OMO! Healthy Snack menjadikan iklan brand OMO! Healthy Snack sebagai medium edukasi jajanan sehat bagi ibu-ibu. Penelitian ini ingin berkontribusi pada studi tentang komunikasi khususnya komunikasi brand dengan menggarisbawahi proses aktif para konsumen dalam memaknai simbol-simbol yang ditampilkan oleh pemilik brand melalui tampilan iklan.

Kata Kunci: periklanan; kepedulian merek; fenomenologi; media sosial; interaksi simbolis

Verlita Evelyn Raimond's email: eveverlita@gmail.com

Para penulis menyatakan tidak mempunyai konflik kepentingan dalam penelitian dan penerbitan publikasi ini.

Copyright (C) 2021 (Verlita Evelyn Raimond).

Licensed under the Creative Commons Attribution-NonCommercial-ShareAlike 4.0 (CC BY-SA 4.0)Available at http://caraka.web.id

Submitted: 3 Juni 2021, Revised: 25 Agustus 2021, Accepted: 30 December 2021 


\section{PENDAHULUAN}

Media sosial adalah media yang muncul seiring lahirnya internet dan mengubah paradigma berkomunikasi menjadi tidak lagi terbatas jarak, waktu, ruang (Watie, 2016). Pada konteks komunikasi strategis, media sosial berperan penting pada bagaimana khalayak akan membicarakan suatu badan (organisasi, lembaga, perusahaan) tanpa harus terlibat langsung (Lewis \& Nichols, 2014). Di Indonesia, pengakses media sosial di Indonesia semakin bertambah; dari April 2019-Januari 2020 ada pertambahan 8,1\% atau 12 juta pengakses (Hootsuite, 2020). Pada dunia perekonomian, media sosial telah berpengaruh pada kegiatan jual-beli (Indoworo, 2016).

Pemanfaatan akun media sosial, termasuk juga Instagram, merupakan salah satu cara untuk mempromosikan produk atau mengiklankan suatu barang dan jasa (Rahman \& Panuju, 2017; Riandy \& Oktavianti, 2019; Untari \& Fajariana, 2018). Instagram menempati urutan ke3 setelah Whatsapp dan Youtube dalam hal media sosial yang sering digunakan. Instagram memiliki presentase sebesar $86.6 \%$, belum lagi kebiasaan dari penduduk Indonesia yang meluangkan waktu di media sosial rata-rata sebanyak 3 jam 14 menit (Hootsuite, 2020). Instagram merupakan sebuah media sosial yang dipelopori Kevin Systrom dan Mike Krieger pada tahun 2010 dan digunakan untuk mengirimkan foto atau video untuk dikelola serta dibagikan secara instan, seperti kata-kata yang membentuknya yaitu instant dan telegram (Ghazali, 2016; Sendari, 2019).

Brand merupakan konsekuensi dari strategi segmentasi pasar dan diferensiasi produk (Maurya \& Mishra, 2012). Brand terkomunikasikan dari pemiliknya (si pemberi pesan) kepada konsumennya (si penerima pesan) melalui beragam sarana, misalnya kemasan, logo, jingle, dan lain-lain. Iklan juga merupakan salah satu sarana tersebut. Iklan merupakan pengumuman ketersediaan barang dan jasa yang melibatkan proses persuasi serta pengiriman makna dan konten (Beasley \& Danesi, 2010).

Pengkomunikasian brand diharapkan memunculkan brand awareness. Brand awareness adalah seberapa aware (sadar) calon konsumen tentang brand tertentu dan hal ini tidak dapat lepas dari upaya pemilik brand untuk menanamkannya (Gustafson \& Chabot, 2007). Mancuso \& Tonelli (2014) berargumen, persoalan brand dari perspektif pemilik dan konsumen dapat dikaji dengan pendekatan fenomenologi yang berfokus pada perspektif dan pengalaman manusia. Kim \& Hall (2014) yang mengkaji hal serupa, menggunakan pendekatan interaksionisme simbolik yang mengedepankan terbentuknya makna suatu brand melalui proses interaksi manusia (konsumen dan pemilik brand).

Penelitian ini mengambil studi kasus berupa brand OMO!! Healthy Snack. Semangat yang diusung dan ide yang ditawarkan oleh brand tersebut sangat signifikan untuk dikaji berkenaan dengan problematika makanan ringan anak-anak Indonesia. Jajanan tidak sehat membuat anak terpapar resiko kesehatan jangka pendek (keracunan) mau pun jangka panjang (gangguan pencernaan yang menyebabkan status gizi buruk dan menggangu prestasi anak di sekolah), sehingga anak perlu pendampingan dalam memilih jajanan yang sehat (Nurbiyati, 2014). Sehingga, dibutuhkan peran serta semua pihak diperlukan untuk memastikan agar anak dapat selalu mengakses jajanan yang memiliki nilai gizi yang baik atau memenuhi kriteria makanan sehat (Febry, 2010).

Beberapa penelitian tentang brand dan iklan sudah dilakukan di Indonesia, seperti Wahid dan Puspita (2017); Djamereng (2018); Sujatmiko (2018); Asri (2018); Wienanda dan Liani (2019), Widyaswari \& Widnyana (2019), Wirasari \& Ferdiana (2018), dan Narida (2020), Sudrajat dan Alvita (2020), Hidayati, Conita, Hadiprawiro (2021). Namun penelitian tersebut berfokus pada perspektif pemilik brand atau konsumen serta menggunakan kerangka konseptual analisis konten dan semiotika.

Penelitian ini berbeda dengan kajian terdahulu sebab secara spesifik mengangkat isu 
brand awareness dengan mengurai perspektif, pengalaman, serta interaksi pemilik brand dan konsumen, berfokus pada iklan di media sosial Instagram, serta menggunakan kerangka konseptual fenomenologi dan interaksionisme simbolik.

Rumusan masalah dalam kajian ini adalah bagaimana kemenarikan iklan brand OMO! pada pembentukan brand awareness OMO! Healthy Snack ditinjau dari perspektif teoritis fenomenologi dan interaksionisme simbolik. Fokus penelitian ini adalah pengkomunikasian brand OMO!! Healthy Snack melalui sarana iklan di akun Instagram OMO!! Healthy Snack. Tujuan penelitian ini untuk menganalisis secara fenomenologi dan interaksionisme simbolik pada terbentuknya brand awareness OMO! Healthy Snack pada iklan di media sosial Instagram.

\section{Fenomenologi}

\section{KERANGKA TEORI}

Fenomenologi merupakan perspektif yang dikembangkan oleh Edmund Husserl untuk menekankan pentingnya pengalaman sadar dalam aspek kognitif dan persepsi manusia, yang sudah diadopsi berbagai bidang keilmuan dan tidak terkecuali juga IImu Komunikasi (M Danesi, 2013). Kajian mengenai konsumen adalah persoalan yang diurai dengan bantuan pendekatan fenomenologi (Kelleher \& Peppard, 2011).

Kelleher \& Peppard (2011) merinci secara detail fenomenologi sebagai berikut: (1) melibatkan eksplorasi reaksi, pikiran, dan perasaan konsumen; (2) mengedepankan pengalaman subyektif konsumen sebagai data yang lebih penting daripada pengamatan eksternal terhadap tindakan konsumen; (3) menguak realitas dan pengalaman konsumen adalah hal beragam yang terkonstruksi secara individual dan sosial.

Fenomenologi digunakan untuk mengkaji brand dari sudut pandang pemilik brand. Berbeda dengan konsumen yang merupakan sekelompok orang homogen, pemilik brand mengacu pada orang-orang heterogen yang bekerjasama, yaitu pemilik utama dari suatu usaha, bagian marketing dan periklanan, dan lain sebagainya. Tugas marketing dapat dikaji dengan fenomenologi, yaitu dengan berfokus pada pengalaman para pekerja yang bertugas di bagian marketing pada suatu perusahaan (Svensson, 2007). Pendekatan fenomenologi sesuai untuk mempelajari dan menangkap pengalaman pemilik usaha atau wiraswasta (Berglund, 2015).

\section{Interaksionisme Simbolik}

Interaksionisme simbolik diperkenalkan oleh Herbert Blumer (1969) dalam bukunya Symbolic Interactionism: Perspective and Method. Blumer berpendapat, makna akan muncul dalam proses interaksi antara manusia. Semua makna, dalam penekanan Blumer, adalah sesuatu yang secara konstan dan dibentuk melalui proses interpretatif (Watson \& Hill, 2015). Fokus interaksionisme simbolik adalah, manusia saling bertukar bahasa dan simbol, serta tiap manusia memiliki keunikan interpretasi dan sudut pandang subyektif mengenai kehidupan (Carter \& Fuller, 2015).

Proses komunikasi dalam interaksionisme simbolik merupakan intentioned communication, bahwa manusia adalah makhluk yang memiliki kemampuan berbahasa yang mengirimkan kata/frasa bermuatan makna lalu memicu respon dari orang lain yang menerima pesan, serta manusia memiliki maksud dan tujuan dalam berkomunikasi. Lebih rinci, dalam strategi komunikasi misalnya, pesan akan dirangkai untuk mendapat hasil yang diharapkan, sehingga diperlukan adanya motive and intent toward a desired goal (riset dan rencana), interaction (implementasi dan kampanye komunikasi) dan gauging of reaction (umpan balik dan evaluasi) (Braun, 2015). Interaksionisme simbolik juga berfungsi menjelaskan proses negosiasi dan bagaimana seorang memahami lingkungannya melalui 
interaksi sosial. Selain itu, seorang manusia tidak hanya berinteraksi dengan orang lain, melainkan juga berkomunikasi dengan dirinya sendiri di alam pikirannya sebagai proses interaksi (Littlejohn, 2017).

Riset pemasaran yang dilakukan oleh Ligas dan Cotte (1999) secara spesifik menggunakan interaksionisme simbolik dan menggabungkannya dengan identifikasi tiga lingkungan (lingkungan pemasaran, individual, dan sosial) yang berperan membangun makna brand. Makna dari satu lingkungan itu mempengaruhi tingkat penerimaan dan negosiasi makna di lingkungan lainnya, serta setiap lingkungan pada dasarnya memilki peran penting dalam membangun makna brand (Kim \& Hall, 2014). Penelitian ini mengungkap dua poin penting penggunaan interaksionisme simbolik dan hubungannya dengan brand, yaitu (1) pemasar (marketer) adalah pencipta makna simbolik dari brand dan mengkontekstualisasikan ke dalam kehidupan kultural serta (2) pemahaman dan preferensi pembeli/pelanggan terhadap sebuah brand sebenarnya berdasarkan makna yang terbentuk dalam konteks dan situasi sosial dari individual (Kim \& Hall, 2014).

\section{Brand Awareness}

Pengupayaan brand awareness melibatkan: (1) kekuatan dan konsistensi pesan; (2) identifikasi dan pemahaman target customer; (3) pembuatan nama perusahaan, logo, slogan; (4) nilai tambah melalui pengemasan, layanan, event spesial; (5) periklanan; dan (6) follow up dengan pelanggan (Gustafson \& Chabot, 2007).

Terbentuknya brand awareness pada pembeli mau pun calon pembeli melibatkan proses berisi level, yaitu unaware (ketidaktahuan sama sekali terhadap brand); recognition (kenal terhadap brand) atau level terendah dan disebut aided recall (pengingatan terbantu); recall (ingat terhadap brand) yang juga disebut unaided recall (pengingatan tidak terbantu); dan top of mind (kesadaran konsumen level tertinggi) (Tritama \& Tarigan, 2016).

Brand awareness menyangkut kemampuan konsumer untuk mengidentifikasikan brand, mengatribusinya pada kategori produk, hingga mengukuhkannya sebagai satu-satunya representasi dari kategori itu (Burmann et al., 2017). Burmann et al (2017) mengutip Aaker, brand awareness diukur dengan: (1) brand recall, yaitu kemampuan orang untuk mengingat trademark, logo, atau kombinasi dari kedua hal itu; (2) brand recognition, yaitu kemampuan mengenali yang terkait dengan akustik (bunyi) atau bantuan visual; dan (3) brand familiarity yang bisa dilihat dari perasaan subjektif untuk merasa familiar dengan satu brand tertentu. Semua manifestasi brand awareness secara fundamental memiliki relevansi dengan keputusan seorang konsumer untuk membeli brand (Burmann et al., 2017).

\section{Media Sosial Instagram}

Pengertian mendasar dari media sosial adalah media yang menyediakan mekanisme kepada audiens untuk terhubung, berkomunikasi, dan berinteraksi dengan satu sama lainnya melalui pesan instan atau situs jejaring sosial (McCay-Peet \& Quan-Haase, 2017).

Pada media sosial, konsumen dapat berkomunikasi secara langsung dan instan dengan berbagai perusahaan sehingga konsumen dapat menyampaikan pendapat dan perusahaan pun dapat mengidentifikasi produk mana yang menarik minat konsumen (Palangi, 2013). Instagram dikembangkan sedemikian rupa sebagai aplikasi mobile yang dapat diakses berbagai OS (operating system) untuk mengambil gambar, mengubah dan lalu mempublikasikan foto atau video hingga dapat dilihat, disukai, dan dikomentari oleh sesama penggunanya yang lain (Winarso, 2015).

Instagram dalam kajian ilmu komunikasi diartikan sebagai medium dari praktik komunikasi yang berkembang seiring dengan meluasnya budaya visual di media sosial. Citra visual, video dan elemen dari story yang ada di instagram adalah bagian krusial dari cara 
berkomunikasi di media sosial. Instagram pada dasarnya platform media sosial namun lebih mengutamakan fokus visual (Leaver et al., 2020). Pemanfaatan media sosial Instagram pun telah menjadi cara untuk mempromosikan produk atau mengiklankan suatu barang dan jasa (Riandy \& Oktavianti, 2019).

\section{Advertising (Iklan)}

Secara etimologis, advertising berasal dari kata advertere yaitu mengarahkan perhatian seseorang dan mengacu pada pengertian etimologis ini maka advertising adalah jenis atau bentuk pengumuman publik yang bermaksud untuk mengarahkan perhatian seseorang akan ketersediaan, kualitas, biaya dari komoditas atau layanan jasa tertentu (Beasley \& Danesi, 2010). Pengiklan menggunakan beragam teknik presentasi dan pembuatan teks, serta teknik yang paling mendasar adalah menciptakan "kepribadian" suatu produk yang dapat diidentifikasi oleh konsumen (Marcel Danesi, 2013).

Mayoritas teori periklanan berpandangan bahwa efektivitas iklan bergantung pada prinsip dan praktik paparan (exposure) dan/atau pengulangan, bahwa (1) mengekspos iklan produk atau merek kepada konsumen dapat menghasilkan peningkatan rasa suka terhadap produk atau merek itu, dan (2) pengulangan ekspos itu dari waktu ke waktu dapat menyebabkan konsumen terkondisikan untuk mungkin lebih menyukai atau memikirkan atau memiliki perasaan tertentu terhadap produk atau merek (Dacko, 2008).

\section{METODE PENELITIAN}

Pendekatan penelitian ini adalah paradigma interpretif. Paradigma interpretif memandang realitas sosial sebagai hal yang utuh, kompleks, dinamis, sarat makna, dan gejalagejalanya berhubungan secara interaktif (Sugiyono, 2013). Paradigma interpretif juga bisa mengandalkan kegiatan interpretasi atas makna yang dihasilkan sesuai dengan perspektif teoritis interaksionisme simbolik dengan menggarisbawahi pemahaman subjektif, persepsi tentang orang, simbol, dan objek (Lune \& Berg, 2017).

Penelitian ini menggunakan metode kualitatif. Metode kualitatif adalah metode yang berada pada rumpun paradigma interpretif dan berupaya untuk memahami kehidupan sosial individu atau kelompok pada peristiwa tertentu (Samsu, 2017). Kehidupan sosial yang akan ditelaah dalam penelitian kualitatif ini mencakup emosi, empati, motivasi, simbol dan maknanya, serta sejumlah hal subjektif yang terasosiasikan pada individu atau kelompok (Lune \& Berg, 2017).

Proses penggalian sumber data pada penelitian kualitatif dilakukan secara purposive (tertuju), yaitu orang-orang yang tahu tentang situasi sosial yang sedang dikaji (Sugiyono, 2013). Subyek penelitian ini adalah, yang pertama, pembeli/pelanggan OMO! Healthy Snack sebab penelitian ini hendak mengungkap perspektif dan pengalaman orang-orang tersebut serta menganalisisnya dalam kerangka brand awareness. Subyek yang kedua adalah pemilik brand. Perspektif dan pengalaman pemilik brand tidak dapat dikesampingkan sebab, sebagaimana telah ditelaah sebelumnya, terbentuknya brand awareness terhadap pembeli/pelanggan dan calon pembeli/pelanggan adalah hal yang diusahakan oleh pemilik brand. Pemilik brand dalam hal ini mengacu pada kesatuan orang, yaitu pemilik utama dari suatu usaha, perancang brand, bagian marketing, bagian periklanan, dan lain sebagainya.

Pada penelitian ini, peneliti mengadakan wawancara kepada lima orang pembeli dan dua orang pemilik brand. Seluruh informan dalam penelitian ini memakai pseudonym (nama samaran) untuk melindungi privasi dan identitas subyek penelitian. Sampai tahun 2021, distributor brand OMO! sudah tersebar di 26 kota di Indonesia serta mencakup lebih dari 200 toko di Indonesia (Jasmine Production House, 2021). Keterangan tersebut memperlihatkan bahwa penelitian mengenai brand $\mathrm{OMO}$ ! berpotensi untuk diadakan pada lingkup nasional 
Indonesia. Meskipun demikian, lokasi penelitian ini difokuskan pada cakupan wilayah DKI Jakarta.

Penggalian data dalam penelitian ini memakai teknik wawancara untuk memahami bagaimana persepsi dari orang yang diteliti atau mempelajari bagaimana orang tersebut memahami makna sebuah fenomena atau peristiwa tertentu (Lune \& Berg, 2017). Pada penelitian ini wawancara dilangsungkan dua tahap. Sebagaimana wawancara dalam penelitian kualitatif yang idealnya tidak dilakukan secara terstruktur. Artinya wawancara dalam penelitian ini berlangsung tidak dengan kaku dan berdasarkan pada panduan wawancara (Lune \& Berg, 2017). Periode dilakukan selama dua minggu di bulan September 2021, dan dibagi dalam dua tahap wawancara.

Pada tahap pertama, peneliti menelaah pengalaman informan yang berasal dari pembeli/pelanggan ketika melihat iklan OMO! di Instagram sehingga informan lalu menjadi kenal dan ingat dengan OMO!. Sementara informan yang berasal dari pemilik brand akan diajak untuk mengeksplorasi pengalaman terkait dengan kegiatan merancang iklan OMO! di Instagram OMO!. Pada tahap kedua, wawancara berfokus pada aspek kemenarikan iklan OMO! baik bagi informan dari pembeli dan pemilik brand OMO!. Informan terlibat dalam proses menafsirkan secara simbolis iklan $O M O$ ! dengan tema pertanyaan seperti penegasan keunggulan brand dan nilai yang ditonjolkan dalam iklan brand OMO!

Keabsahan data dalam penelitian ini antara lain credibility, transferability, dependability, dan confirmability (Sugiyono, 2013), yang dirinci sebagai berikut: (1) Credibility dilakukan dengan memperpanjang durasi penelitian, meningkatkan ketekunan meneliti, triangulasi, analisis kasus negatif, menggunakan bahan referensi, mengadakan member check; (2) Transferability, nilai transfer yang bergantung pada pembaca dan peneliti sendiri tidak dapat menjamin validitas eksternal ini; (3) Dependability diuji dengan cara melakukan audit terhadap keseluruhan proses penelitian dan dilakukan oleh auditor independen; (4) Uji confirmability, menguji hasil penelitian yang dikaitkan dengan proses yang dilakukan.

Analisis data dalam penelitian kualitatif memiliki tujuan untuk memudahkan penjelasan dan memberikan pengertian dalam bentuk yang lebih sistematis dari sebuah hasil wawancara dan temuan di lapangan (Samsu, 2017). Analisis data dalam penelitian ini mengikuti pendapat Creswell (2015) yang menjelaskan proses analisis data sebagai berikut: (1) menyiapkan dan mengorganisasikan data (seperti transkrip dan foto) untuk dianalisis; (2) reduksi data untuk menjadi tema melalui proses pengkodean dan peringkasan kode; (3) penyajian data dalam bentuk bagan, tabel, atau pembahasan.

Kegiatan analisis data pada penelitian ini juga menggunakan teori fenomenologi dan interaksionisme simbolik yang telah dipaparkan pada bagian tinjauan literatur. Dengan begitu, proses analisis data dalam penelitian ini adalah memperlakukan kegiatan dan tindakan manusia sebagai kumpulan simbol yang memiliki lapisan-lapisan pemaknaan (Lune \& Berg, 2017).

\section{HASIL PENELITIAN}

Brand OMO! mengusung visi yaitu menjadi produsen makanan terpercaya dan berkontribusi untuk menjadikan anak Indonesia lebih sehat, serta misi berupa menciptakan snack (makanan ringan) sehat untuk anak yang bisa hadir pada top of mind para ibu dan anak, dan memberikan pesan tentang pentingnya kesehatan dan perkembangan gizi anak (Jasmine Production House, 2021). Kemunculan OMO! dilatarbelakangi kekhawatiran founder kepada kedua anaknya saat mencari makanan ringan sehat untuk pendamping ASI (Jasmine Production House, 2021). Pada 15-16 Desember 2018, OMO! dinobatkan sebagai juara 1 dalam acara MakerFest 2018 (Jasmine Production House, 2021). 


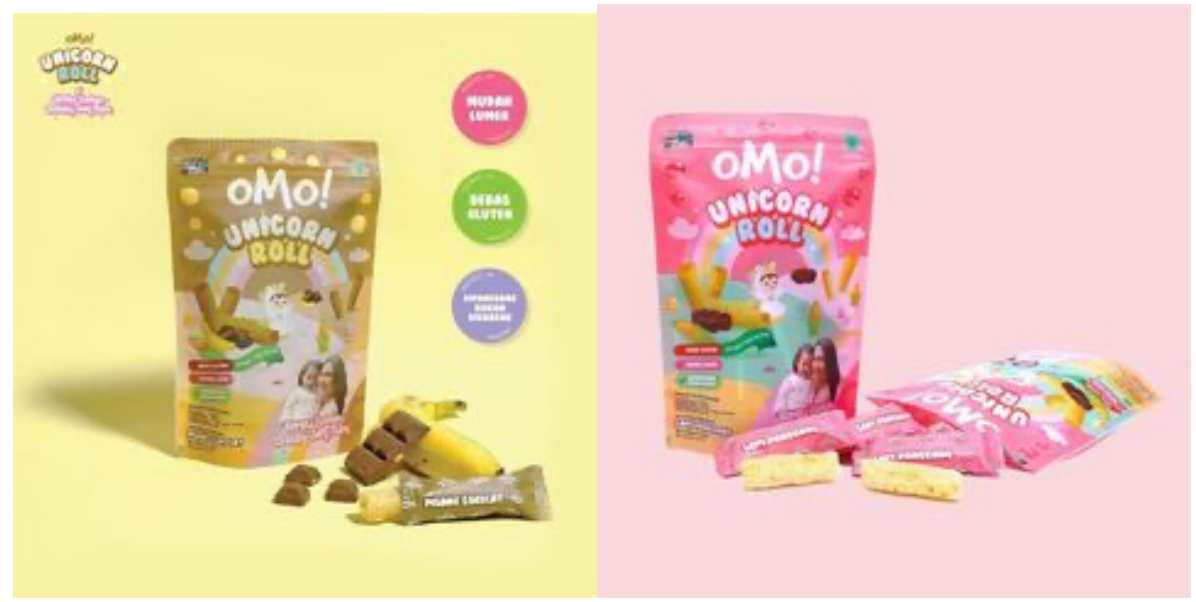

Gambar 1. Varian OMO! Sumber: Jasmine Production House, (2021).

Pada penelitian ini, semua informan pembeli OMO! sepakat bahwa iklan OMO! sudah baik sebab memenuhi keinginan terhadap jajanan sehat bagi anak-anak. Secara keseluruhan tema yang muncul dari informan pembeli adalah menariknya aspek visual Iklan OMO! yang dekat dengan dunia anak-anak serta istilah sehat yang melekat dalam iklan brand OMO!. Sementara semua informan pemilik brand OMO! setuju bahwa iklan OMO! memegang nilai edukasi jajan sehat bagi kalangan ibu-ibu. Secara keseluruhan tema yang muncul dari informan pemilik brand adalah iklan brand OMO! sebagai sarana edukasi dan penyampaian nilai perusahaan $O M O$ ! ke target konsumen

\section{Iklan brand OMO! memiliki ketertarikan visual}

Informan As yang memiliki anak satu menyatakan, dirinya merasa penasaran terhadap OMO! Produk yang dirilis oleh OMO! bagi informan As adalah produk menarik sebab menyajikan cemilan MSG versi sehat dan buat anak-anak. Sementara dari kenampakan iklan yang ditampilkan oleh brand OMO! di Instagram. Informan As merasa tertarik karena aspek visual yang identik dengan dunia anak-anak (dalam hal aspek tokoh atau karakter fiksi) dan karena mengenal bintang iklannya secara personal. Informan berkata

\footnotetext{
"Yang bikin nempel iklan OMO! itu karena ada gambar unicorn jadi itu buat anak-anak deh pastinya. Menariknya lagi ada foto dua balita dan foto anak dan teman saya" ( Informan As, Wawancara, 11/9/2021)
}

Informan Ra juga menyatakan hal yang sama, ia terdorong oleh rasa penasaran dan ketertarikan dengan aspek visual yang identik dengan keceriaan dunia anak-anak seperti warna dan juga aspek tokoh-tokoh atau karakter. Informan Ra juga menjelaskan keyakinannya dalam membeli produk $O M O$ ! sebab tampilan visualnya. Seperti kutipan wawancara berikut, 
"Yakin dong, iklan makanan itu tampilannya harus terang, ga boleh berantakan apalagi gelap dan OMO! udah menarik dari warnanya sehingga sudah buat orang bisa tertarik " (Informan Ra, Wawancara, 11/9/2021)

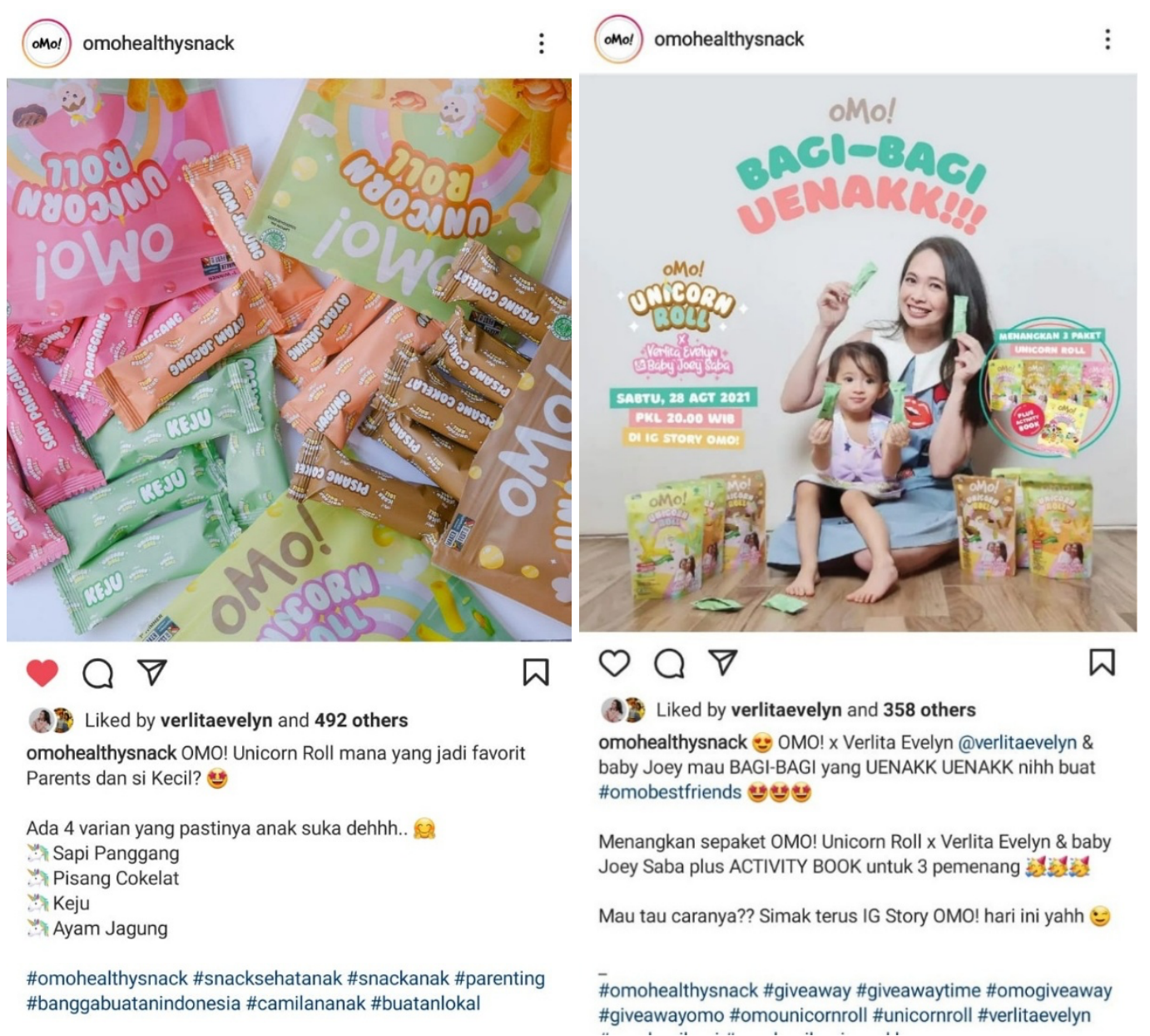

Gambar 2. Screenshoot iklan OMO! di Instagram yang mendorong pembeli mengonsumsi OMO! Sumber: akun instagram $O M O$ !

Informan Ra juga menjelaskan, ia merasa penasaran terhadap produk itu sendiri. Informan Ra berasumsi OMO! sebagai produk yang layak dijadikan opsi jajanan anak dan menarik karena mengedepankan aspek kesehatan. Informan Ra merasa tertarik karena aspek visual yang identik dengan dunia anak anak (dalam hal warna dan juga aspek tokoh-tokoh atau karakter), bintang iklannya, dan iklan OMO! sangat informatif. Seperti dalam nukilan wawancara berikut ini,

Q: Cerita, dong tentang pengalaman Anda ketika melihat iklan $O M O$ ! di Instagram, sehingga Anda lalu menjadi kenal dan ingat dengan OMO!. Istilahnya, gara-gara lihat iklan $O M O$ ! itu, OMO! jadi seperti lengket di kepala Anda?

A: Wah, snack apa nih?! Option baru buat anak. Colorfull (memiliki banyak warna menarik) dan lagi kolaborasi sama teman saya yang menjadi bintang iklan di brand OMO!. lya mungkin menarik karena cukup ditekankan "healthy" sehingga "secara keseluruhan iklannya. easy on eyes dan informatif, colorful kayak minta diklik, so Yes". (Informan Chi, Wawancara, $14 / 9 / / 2021)$

Beberapa informan pembeli juga langsung mewujudkan rasa penasaran tersebut dengan membeli produk $O M O$ !, seperti yang dituturkan informan Ad. 
"Langsung beli kak kan aku ke online shop tuh! haha, kemudian chat bintang iklannya yang kebetulan saya kenal, bahwa aku mau beli secara online. Gercep (gerak cepat) aku anaknya haha" (Informan Ad, Wawancara, 15/9/2021)

Informan Ri menuturkan bahwa yang terpikirkan saat melihat iklan OMO! bahwa produk ini adalah cemilan yang cocok buat anaknya yang masih balita.

"Yang bikin inget sama iklan OMO! karena ada teman saya yang menjadi bintang iklannya, selain itu karena bahan-bahan yang terkandung dalam OMO! sangat natural jadi aman untuk anak aku" (Informan Ri, Wawancara, 15/9/2021).

Inform Ri juga menyatakan bahwa iklan yang ditampilkan iklan OMO! sudah sangat menarik dan bagus ditambah dengan packaging produk OMO! yang sangat colourfull dan kandungan gizi yang sehat dan aman sehingga menambah keyakinan untuk membeli produk OMO!

"Saya setelah melihat iklan dan merasa produknya sudah bagus. Saya ini kalau mau beli untuk makanan biasanya saya baca komposisinya yang tertera dalam postingan instagram atau membaca deskripsi produk di aplikasi belanja online, kemudian periksa harganya apakah produknya terjangkau atau tidak" (Informan Ri, Wawancara, 15/9/2021)

Hal ini cukup berbeda dengan pendapat informan Is yang mengaku harus mencari referensi atau pendapat orang lain tentang brand OMO! atau produk makanan yang membawa istilah sehat dalam produknya. Informan Is menjelaskan saat proses memilih makanan bagi anak-anak, ia terlebih dahulu akan melihat dulu review produk di website. Pada laman review produk tersebut ia akan fokus pada komentar para konsumen tentang produk yang bersangkutan sebelum pada akhirnya memutuskan produk tersebut sehat atau tidak. Informan Is mengasosiasikan brand OMO! dengan dunia anak-anak dan brand ini sesuai sekali dengan anak-anak, dari aspek visual yang identik dengan dunia anak-anak (dalam hal warna dan juga tokoh atau karakter fiksi) serta dari dirinya yang concern terhadap jajanan anak yang sehat.

"Saya pertama lihat produk OMO! langsung relate ke anak-anak. Mungkin anak cewek kali
ya?! Ada warna pink, packagingnya girly colour. Kalau saya hanya melihat warnanya saja dan
tidak baca tulisannya, itu bisa makanan atau apapun yang relate dengan anak-anak. Kesannya
iklan OMO! ini cheerfull dan menampilkan happy faces anak-anak, artinya makan OMO! bikin
happy. Lucu banget tampilan iklannya, warnanya catchy, lagunya anak-anak banget.
Packagingnya menurut saya juga lucu sehingga melihat muka anak-anak di iklan OMO!
membuat iklan ini seperti menempel di ingatan saya". (Informan Is, Wawancara, 16/19/2021)

Informan Is menjelaskan bahwa ia sudah sudah mencoba beberapa produk OMO! dan anaknya suka sehingga ia yakin dengan produk ini. Informan Is menyatakan dirinya adalah ibu yang concern dengan kesehatan sehingga ingin lebih digarisbawahi lagi komposisi produk OMO!. Informan Is ingin mendapatkan informasi gizi yang lebih banyak seperti bebas gluten dan masih banyak lagi.

\section{Iklan brand OMO! sebagai sarana edukasi}

Informan St sebagai founder OMO! Healthy Snack menyatakan, ia menggunakan dua kategori iklan yaitu iklan soft selling dan hard selling. Soft selling mengacu pada edukasi agar ibu-ibu memiliki info yang valid. Hard selling memfokuskan kepada produk yang sehat untuk 
anak-anak. Informan St sangat mengharapkan kesegeraan pencerapan pesan iklan bagi calon konsumen. Informan St juga ingin menjadikan OMO! sebagai perusahaan makanan yang terpercaya baik dari mutu, kualitas, dan komitmen.

\begin{abstract}
"Saat merancang iklan, kami membuat dua jenis iklan yaitu soft selling dan hard selling. Soft selling ini lebih ke edukasi jadi memang untuk ibu-ibu yang memerlukan info-info yang valid dan penting untuk anak. Untuk hard selling lebih ditiitikberatkan ke produk yang sehat untuk anak-anak. Kami sangat mengharapkan saat orang pertama kali melihat (iklan), ga lebih dari tiga detik udah nangkep pesannya. Pesan lain adalah menjadi perusahaan makanan anak yang terpercaya baik dari mutu, kualitas, dan konsumen." (Informan St, Wawancara, 11/9/2021)
\end{abstract}

Hal ini dibenarkan oleh informan bernama Ro yang merupakan bagian marketing.

\begin{abstract}
"Iklan adalah medium penyampaian nilai OMO! ke target konsumen. Nilai yang diterapkan di setiap konten, feed, dan story postingan di Instagram adalah memberikan edukasi tentang makanan sehat dan bernutrisi kepada ibu-ibu. Makanan sehat tanpa MSG, digoreng, pengawet. Makanan sehat adalah makanan yang penting bagi anak di masa tumbuhkembang di golden age (usia 0-5 tahun). OMO! adalah pilihan tepat bagi mommymommy, sebab OMO! secara harga tidak terlalu mahal, kualitas dalam pembuatan, kualitas dari segi fungsi snack itu sendiri" (Informan Ro, Wawancara, 11/9/2021)
\end{abstract}

Selain itu, informan Ro juga menekankan, iklan brand OMO! bertujuan untuk memberikan pengetahuan kepada konsumen bahwa OMO! snack pilihan tepat bagi ibu-ibu cerdas sebab harganya terjangkau tidak terlalu mahal dan berkualitas. Iklan OMO! juga menampilkan para ahli makanan sehat seperti nutritionis dan ahli gizi untuk bisa memberikan saran, informasi, pilihan mengenai makanan yang diperlukan bagi tumbuh kembang anak. Terkait posisi brand OMO! di antara brand lainnya, informan pemilik brand bernama St menyatakan, pada dasarnya iklan OMO! di Instagram belum mendalam dan posisinya masih mirip dengan beberapa produk lain. Saat ini brand OMO! akan memprioritaskan edukasi ke masyarakat khususnya masalah makanan higienis. Informan St juga menitikberatkan edukasi bersama ahli gizi untuk pelurusan berbagai rumor terkait makanan sehat yang berkembang di masyarakat.

\footnotetext{
"Banyak banget sekarang yang kasih label "anak dan sehat" tapi sebetulnya mereka ga ada standar aman pangannya sama sekali, sedangkan produk OMO! ini, benar-benar menjaga kualitas "sehat". Karena banyak produk serupa yang berani nulis cemilan sehat padahal prosesnya ga sama sekali. Kita ijin dari BPOM (Badan Pengawas Obat dan Makanan) semua jelas" (Informan St, Wawancara, 21/9/2021)
}

Hal yang cukup berbeda dipaparkan oleh informan Ro yang menyatakan, posisi iklan OMO! dibanding iklan serupa lainnya sudah cukup baik. Iklan OMO! sudah banyak menampilkan banyak pesan, informasi dan edukasi atau tips yang sudah ditangkap konsumer sehingga daya jual iklan $O M O$ ! di instagram sudah lebih baik daripada sebelumnya. Namun perlu ada improvisasi lebih lanjut supaya posisi iklan lebih baik, sehingga untuk ke depan brand $O M O$ ! akan banyak memberikan edukasi, informasi tentang lisensi halal dari BPOM dan tips sesuai target pasar kami.

Q: Hal apa selain tulisan "healthy" dalam iklan $O M O$ ! yang anda inginkan agar konsumen tahu bahwa "OMO! adalah snack sehat"?

A: "Selain kata sehat, snack kami menampilkan pula kepemilikan lisensi halal dari BPOM. 
Dibanding brand lainnya yang harganya mirip dengan $O M O$ ! kami sendiri punya kualitas mumpuni. Kami punya kemampuan untuk menghadirkan fresh production yang baik dan memang bermanfaat dan serta proses produksinya diatur ketat oleh kami" (Informan Ro,Wawancara, 22/9/2021).

Selain itu, iklan $O M O$ ! juga sudah mengupayakan penegasan identitas sebuah brand sehingga mudah diingat oleh target konsumen.

Q: "Bagaimanakah wujud iklan $O M O$ ! di Instagram yang Anda rancang sehingga memenuhi nilai edukasi bagi para konsumen tentang pentingnya makanan sehat sekaligus bisa mencapai unsur kesegaraan pencerapan informasi bagi calon konsumen?"

A: "Iklan OMO! memiliki nilai edukasi baik secara visual dan jingle. Memang inbound marketing kita tujuannya memang menarik mata lebih dahulu, keinginan membaca terlebih dahulu. Warna-warna yang menarik tidak sering digunakan kami sudah memilih warna standout, pastel, biru muda, pink muda, oranye muda, warna yang khas anak-anak diberikan icon-icon $O M O$ !, ada motion juga sehingga muncul keceriaan saat mendengar iklan motion tersebut. Ide utama dalam iklan OMO! adalah memberikan reminder, kalau warna ini OMO!, jingle ini adalah $O M O$ !, orang akan mudah ingat OMO!, OMO!, OMO!, dan OMO! adalah bagian kehidupan anak-anak" (Informan Ro, Wawancara, 22/9/2021)

Dalam beberapa postingan instagram, pihak OMO! juga menghadirkan ahli gizi untuk meyakinkan pembeli bahwa brand OMO! sudah memenuhi aspek kesehatan.

"Konsultan gizi kami hadirkan dalam konten instagram untuk memberikan edukasi seputar superfood, cara mengatasi gtm (gerakan tutup mulut) pada balita atau bayi, stunting, dan langkah preventif ketidakbaikan nutrisi bagi anak-anak". (Informan Ro, Wawancara, 22/9/2021)

\section{Kemenarikan iklan brand OMO! dan brand awareness}

Secara mendasar, elemen pertama dalam brand adalah atribut fisik yang mudah diidentifikasi dan dikenali. Kedua, adalah karakteristik fungsional yang membuat konsumen akan berulang-ulang menggunakan produk yang sama. Ketiga, adalah karakteristik. Karakteristik akan membuat brand sangat personal dan menjadi atribut spesifik bagi kehidupan seseorang dan bisa menarik khalayak yang lebih luas akan sadarnya atas makna yang ditimbulkan oleh brand (Ligas \& Cotte, 1999).

Selanjutnya, iklan memiliki peran penting dalam membangun sebuah brand sebab iklan akan menghasilkan nilai simbolis, pesan yang kuat serta kebutuhan yang nampak realistis, sehingga memungkinkan konsumer untuk membentuk hubungan dan ikatan dengan brand layaknya hubungan antar manusia (Kim \& Hall, 2014).

Iklan brand OMO! pada penelitian ini menjadi sangat personal bagi informan pembeli dan penjual sebab berurusan dengan kesehatan anak-anak mereka. Dari kalangan pembeli dan penjual, semuanya menyepakati tentang pentingnya kepedulian dari para ibu-ibu terhadap jajanan sehat bagi anak-anak mereka. Pada penelitian ini brand awareness ditunjukkan oleh para pembeli saat ia mampu mengingat trademark OMO! yaitu foto anak kecil dan logo OMO! yang colourfull. Berikutnya, para konsumer juga mudah mengenali bunyi akustik dari pengucapan OMO!, suara dari motion graphics iklan OMO!, jingle OMO!, dan visual warna yang cerah serta identik dengan anak-anak. Terakhir sisi keakraban para pembeli dengan brand $O M O$ ! banyak terjalin melalui kedekatan personal antara pembeli dengan bintang iklan $O M O$ ! serta perasaan sentimentil berkenaan dengan kebutuhan jajanan sehat 
bagi anak-anak.

Dari hasil wawancara kualitatif, para informan menyatakan rasa ketertarikan visual dalam melihat iklan brand $O M O$ ! dan saat menjumpai kata sehat yang melekat dalam iklan tersebut. Secara fenomenologis, pengalaman konsumen dalam menangkap kemenarikan iklan $O M O$ ! ini diwujudkan dengan langsung menghubungi pihak pengiklan untuk membeli produk yang ditawarkan $O M O$ !. Sementara itu, pengalaman konsumen dalam melihat jajanan tidak sehat pada akhirnya menjadikan produk OMO! sebagai pilihan makanan ringan bagi anak-anak konsumen. Pengalaman tersebut terkorespondensi pula dengan adanya tampilan jajan sehat serta keceriaan ibu dan anak yang tertera dalam iklan OMO!.

Para pemilik brand $O M O$ ! lebih menekankan edukasi makanan sehat agar para calon konsumen sadar, produk OMO! menawarkan jajanan sehat bagi anak-anak dibanding jajanan lainnya. Tahap sadar tentang pentingnya jajanan sehat ini nantinya akan mendorong calon konsumen untuk membeli produk OMO! Pihak pemilik brand juga turut menampilkan warna yang menarik mata dan sesuai dengan nuansa anak-anak sehingga mata calon konsumen tertarik dan calon konsumen bisa menetapkan bahwa OMO! adalah jajanan sehat bagi anakanak. Cara lain untuk membuat konsumen tertarik menurut para pemilik brand adalah dengan menampilkan pendapat dari para ahli gizi di setiap tampilan di instagram. Pendapat para ahli ini penting untuk memudahkan para konsumen dalam mengidentifikasi kategori sehat dalam produk OMO!.

Pada dasarnya interaksionisme simbolik akan melihat bagaimana proses interaksi makna sebuah brand dalam dua cara. Pertama, para pemilik brand menciptakan makna simbolik dari produk atau brand $O M O$ ! sebagai jajanan sehat serta mengkontekstualisasikan secara kultural dalam kehidupan sehari-hari sebagai kaum ibu yang sedang mencari alternatif jajanan sehat. Kedua, para konsumer juga melibatkan secara aktif dalam proses pembentukan brand dan mengirim pesan iklan seperti jajan sehat, tampilan visual ibu dan anak untuk dikoneksikan dengan situasi personal konsumen. Situasi personal ini terwujud dengan minimnya opsi jajanan sehat bagi anak, hingga pada akhirnya konsumen memiliki rasa ingin membeli kepada apapun yang terasosiasikan dengan brand OMO!.

Interaksionisme simbolik juga memperlihatkan bagaimana makna sebuah brand terjalin melalui tiga setting yaitu lingkungan pemasaran, individual, dan sosial (Ligas \& Cotte, 1999). Pada level individual, para konsumer OMO! menafsirkan makna yang dihadirkan oleh para pemasar melalui iklan brand. Dalam proses ini konsumer mengidentifikasi tujuan dan keinginan personalnya seperti keinginan untuk mendapat jajanan sehat untuk anak-anak mereka. Pada lingkungan pemasaran sebuah brand akan terkomunikasikan saat terjadi interaksi antara informasi produk ke calon konsumer. Informasi ini berupa benefit yang didapat konsumen saat menggunakan produk yang bersangkutan seperti informasi dari para ahli gizi tentang jajanan sehat, komposisi jajanan sehat, dan lisensi halal.

Di level lingkungan sosial, makna dari sebuah brand dikomunikasikan lewat simbolisme sehingga proses negosiasi makna antara konsumen dengan brand akan berlangsung. Proses negosiasi makna dalam penelitian ini terjadi saat para pembeli menafsirkan simbol-simbol yang terwujud dalam iklan $O M O$ ! seperti pemilihan warna, tampilan ilustrasi, kenampakan ikon, jingle, dan informasi dari ahli gizi sehingga diterjemahkan oleh para pembeli sebagai simbol jajanan yang sehat bagi anak-anak.

\section{KESIMPULAN}

Penelitian ini menggunakan fenomenologi dan interaksionisme simbolik dalam melihat kemenarikan sebuah iklan di media sosial instagram untuk membangun brand awareness. Secara teoritik, perspektif interaksionisme simbolik menawarkan cara pandang bagaimana sebuah hubungan interaksi antara manusia dengan lingkungan sosialnya. Sementara, 
fenomenologi akan menekankan aspek pengalaman sadar manusia dalam memaknai kehidupan sosialnya. Pada konteks brand awareness, sangat penting bagi sebuah iklan untuk menanamkan kesadaran kepada konsumen tentang pentingnya sebuah produk tertentu. Oleh sebab itu, iklan menggunakan banyak sekali simbol dan tanda untuk mengirim pesan kepada calon pembelinya.

Iklan brand $O M O$ ! mengirimkan pesan tentang jajanan sehat dan pengasosiasian brand $O M O$ ! dengan dunia anak-anak yang disimbolkan melalui tampilan visual yaitu warna yang unik, ceria, foto anak kecil, foto ibu dan anaknya, serta edukasi dari ahli kesehatan. Penelitian ini juga menggarisbawahi beberapa faktor yang membuat para pembeli untuk membeli OMO!, seperti ketertarikan visual, kedekatan personal dengan bintang iklan OMO!, serta iklan OMO! yang mempromosikan jajanan sehat.

Penelitian ini secara keseluruhan berkontribusi pada studi tentang pengkomunikasian brand dengan menitikberatkan proses interaksi pengalaman antara konsumen dengan pemilik brand melalui media iklan.

\section{DAFTAR PUSTAKA}

Alvita, A. C., \& Sudrajat, R. H. (2020). Representasi Kecantikan Kontemporer Pada Perempuan Dalam Iklan (Analisis Semiotika John Fiske Dalam Iklan Nivea\# Extracare For Extra Women). EProceedings of Management, $7(3)$.

Asri, R. (2018). Konstruksi Realitas Kecerdasan Anak: Analisis Semiotik Barthes Iklan Susu Formula Anak di Televisi. Jurnal Komunikasi Dan Kajian Media, 2(1), 43-65.

Beasley, R., \& Danesi, M. (2010). Persuasive signs: The semiotics of advertising. In Persuasive Signs: The Semiotics of Advertising. Walter de Gruyter. https://doi.org/10.1515/9783110888003

Berglund, H. (2015). Between cognition and discourse: Phenomenology and the study of entrepreneurship. International Journal of Entrepreneurial Behavior \& Research.

Blumer, H. (1969). Symbolic interactionism (Vol. 50). Englewood Cliffs, NJ: Prentice-Hall.

Braun, S. (2015). Can we all agree? Building the case for symbolic interactionism as the theoretical origins of public relations. Journal of Professional Communication, 4(1).

Burmann, C., Riley, N.-M., Halaszovich, T., \& Schade, M. (2017). Identity-based brand management. Wiesbaden: Springer Gabler, 10, 973-978.

Carter, M. J., \& Fuller, C. (2015). Symbolic interactionism. Sociopedia. Isa, 1(1), 1-17.

Conita, A., Hadiprawiro, Y., \& Hidayati, A. N. (2021). Iklan Tokopedia Versi BTS sebagai Representasi Korean Waves. Jurnal Desain, 8(2), 188-206.

Creswell, J. W. (2015). Penelitian Kualitatif \& Desain Riset: Memilih di Antara Lima Pendekatan, terj. Ahmad Lintang Lazuardi, Yogyakarta: Pustaka Pelajar.

Dacko, S. (2008). The advanced dictionary of marketing: putting theory to use. Oxford University Press.

Danesi, M. (2013). Phenomenology. In M Danesi (Ed.), Encyclopedia of Media and Communication (p. 514). University of Toronto Press. https://www.jstor.org/stable/10.3138/9781442695528

Danesi, Marcel. (2013). Advertising. In Marcel Danesi (Ed.), Encyclopedia of Media and Communication (pp. 11-23). University of Toronto Press. https://www.jstor.org/stable/10.3138/9781442695528

Djamereng, A. (2018). Analisis Semiotika pada iklan di televisi (Iklan Wardah dan iklan Total Almeera). Jurnal Al-Khitabah, 4(1).

Febry, F. (2010). Kebiasaan Jajan Pada Anak. Jurnal Ilmu Kesehatan Masyarakat, 1(2).

Ghazali, M. (2016). Buat Duit Dengan FB \& Instagram. PTS Publishing House Sdn. Bhd.

Gustafson, T., \& Chabot, B. (2007). Brand awareness. Cornell Maple Bulletin, 105, 1-5.

Hootsuite. (2020). Indonesian Digital Report 2020. 
HOOTSUITE, W. E. A. R. E. S. Y. (2020). Digital 2020. Global Digital Overview. Datareportal.

Indoworo, H. E. (2016). Menumbuhkan jiwa wirausaha melalui peran sosial media. Jurnal Informatika Upgris, 2(1).

Jasmine Production House. (2021). OMO!! Snack for Mom and Baby.

Kelleher, C., \& Peppard, J. (2011). Consumer experience of value creation-a phenomenological perspective. ACR European Advances.

Kim, H.-S., \& Hall, M. L. (2014). Fashion brand personality and advertisement response: incorporating a symbolic interactionist perspective. In T. Choi (Ed.), Fashion Branding and Consumer Behaviors (pp. 29-45). Springer.

Leaver, T., Highfield, T., \& Abidin, C. (2020). Instagram: Visual social media cultures. John Wiley \& Sons.

Lewis, B. K., \& Nichols, C. (2014). Social media and strategic communication: An examination of theory and practice in communication research. In D. Holtzhausen \& A. Zerfass (Eds.), The Routledge handbook of strategic communication (pp. 569-584). Routledge.

Liani, T. A., \& Wienanda, W. K. (2019). Analisis semiotik terhadap iklan Youtube mie sedaap Korean spicy chicken. Jurnal Gama Societa, 3(2), 79-86.

Ligas, M., \& Cotte, J. (1999). The Process of Negotiating Brand Meaning: a Symbolic Interactionist Perspective. Advances in Consumer Research Volume, 26, 609-614. https://www.acrwebsite.org/volumes/8329/volumes/v26/NA-26/full

Littlejohn, S. (2017). Theories of human communication. Waveland Press.

Lune, H., \& Berg, B. L. (2017). Qualitative research methods for the social sciences (9th, Global Edition). Essex: Pearson Education Ltd.

Mancuso, M. S., \& Tonelli, M. (2014). The phenomenological approach: a framework to design markets. Proceedings of the 59th International Council for Small Business World Conference, 4437-4451.

Maurya, U. K., \& Mishra, P. (2012). What is a brand? A Perspective on Brand Meaning. European Journal of Business and Management, 4(3), 122-133.

McCay-Peet, L., \& Quan-Haase, A. (2017). What is social media and what questions can social media research help us answer. The SAGE Handbook of Social Media Research Methods, 13-26.

Narida, M. G. (2020). Brand Image Dalam Persaingan Iklan E-commerce Menggunakan Brand Ambassador (Analisis Semiotika Iklan Shopee 'Bisa Tuku Saiki'versus Tokopedia x BTS). JCommsci-Journal Of Media and Communication Science, 3(1), 12-25.

Nurbiyati, T. (2014). Pentingnya memilih jajanan sehat demi kesehatan anak. Asian Journal of Innovation and Entrepreneurship, 3(03), 192-196.

Palangi, A. (2013). Interactivity. In Marcel Danesi (Ed.), Encyclopedia of Media and Communication (pp. 363-364). University of Toronto Press. https://www.jstor.org/stable/10.3138/9781442695528

Rahman, I. A., \& Panuju, R. (2017). Strategi Komunikasi Pemasaran Produk Fair N Pink Melalui Media Sosial Instagram. WACANA: Jurnal IImiah IImu Komunikasi, 16(2), 214-224.

Riandy, D., \& Oktavianti, R. (2019). Strategi Kreatif Iklan Online Shop Aksesoris Wanita Di Media Sosial Instagram (Studi Pada Akun@ Summercity_Id Dan@ Neve_Blink).Prologia, 3(1), 74-79.

Samsu, S. (2017). Metode Penelitian: Teori Dan Aplikasi Penelitian Kualitatif, Kuantitatif, Mixed Methods, Serta Research \& Development. Pusaka Jambi.

Sendari, A. A. (2019). Instagram Adalah Platform Berbagi Foto dan Video, Ini Deretan Fitur Canggihnya. Diakses Pada Oktober, 19, 2019.

Sugiyono, S. (2013). Metode Penelitian Kuantitatif Kualitatif dan R\&D. Alfabeta.

Sujatmiko, G. (2018). Analisis Semiotika Komunikasi Visual Iklan Minute Maid Pulpy Tahun 
2008-2018. Jurnal Komunikatif, 7(2).

Svensson, P. (2007). Producing marketing: towards a social-phenomenology of marketing work. Marketing Theory, 7(3), 271-290.

Tritama, H. B., \& Tarigan, R. E. (2016). The effect of social media to the brand awareness of a product of a company. CommIT (Communication and Information Technology) Journal, 10(1), 9-14.

Untari, D., \& Fajariana, D. E. (2018). Strategi Pemasaran Melalui Media Sosial Instagram (Studi Deskriptif Pada Akun@Subur_Batik).Widya Cipta: Jurnal Sekretari Dan Manajemen, 2(2), 271-278.

Wahid, U., \& Puspita, A. E. (2017). Upaya Peningkatkan Brand Awareness PT. Go-Jek Indonesia Melalui Aktivitas Marketing Public Relations. Jurnal Komunikasi, 9(1), 31-43.

Watie, E. D. S. (2016). Komunikasi dan media sosial (communications and social media). Jurnal The Messenger, 3(2), 69-74.

Watson, J., \& Hill, A. (2015). Dictionary of media and communication studies. Bloomsbury Publishing USA.

Widyaswari, I. G. A. W., \& Widnyana, I. G. N. (2019). Kajian Iklan TK Widya Kumara Sari di Sosial Media Facebook sebagai Sarana Promosi dan Branding. Senada (Seminar Nasional Desain dan Arsitektur), 2, 295-301.

Winarso, B. (2015). Apa itu Instagram, fitur dan cara menggunakannya. DailySocial. Id. Diakses Dari Https://Dailysocial. Id/Post/Apa-Itu-Instagram.

Wirasari, I., \& Ferdiana, T. (2018). Strategi Kreatif Tema Pahlawan Dalam Iklan Media Sosial Bukalapak. ATRAT: Jurnal Seni Rupa, 6(2). 